\title{
ARCHITECTONICS OF THE VESSELS SUPPLYING AUTOGRAFT OF THE LONG TOE, AND OPTIONS FOR THEIR “CONNECTION” TO THE RECIPIENT VESSELS WHEN TRANSPLANTED TO THE HAND IN CHILDREN
}

\author{
Golyana S.I. ${ }^{1}$, Grankin D.Y.1 \\ ${ }^{\text {I The Turner Scientific Research Institute for Children's Orthopedics, Saint Petersburg, e-mail: grankin.md@gmail.com }}$
}

Aims.

The aim of the study was to show the significance of investigating the microvascular structure of the donor and recipient regions for successful microsurgical autotransplantation of toes in children.

Materials and methods.

From 2000 to 2018, 541 children aged from 8 months to 17 years with congenital and acquired pathology of the upper limb were examined and treated at the RCOI [Research Children's Orthopaedic Institute] n.a. G.I. Turner. A total of 696 autografts were transpositioned.

Results.

Based on the data of this study, we revealed that the graft of the long toe can be supplied from the system of both the anterior tibial artery, and posterior tibial artery. If the dorsal artery of foot is preserved in the distal direction, the sources of blood supply to the long and third toes may be the dorsal and plantar metatarsal arteries. In cases where the dorsal artery of foot and dorsal metatarsal artery 1 were well developed, different combinations of the finger supplying arteries were noted. When the dorsal metatarsal artery was absent or severely hypoplastic, the autograft was isolated on the plantar metatarsal arteries. The main parameters determining the source of blood supply to the graft were adequate diameter and high blood flow intensity. During the study, we found that in the case of blood supply to the graft from the anterior tibial artery (79\%), a well-developed dorsal metatarsal artery was determined in $68 \%$, while in $32 \%$ of cases the blood supply to the graft was performed only through the plantar metatarsal arteries.

Conclusions.

The technique of surgical isolation of the toe autografts remains unchanged and does not depend on the options of angioarchitectonics of the donor region. The survival of the transpositioned microvascular autograft depends on the quality of vessel mobilisation in the donor region and preparation the vessels in the recipient region.

Keywords: microsurgery, autotransplantation of toes to the hand, finger grafting, structure of the foot vessels, anatomy of the donor region

\section{INTRODUCTION}

Angioarchitecture is crucial for successful transplantation of the complexes of tissues. One of the methods of finger reconstruction in patients with post-traumatic and congenital deformities is microsurgical autograft toe-to-hand transfer $[1,2]$. A wide range of post-traumatic and congenital pathologies of upper limbs require profound studies of the angioarchitecture of donor and recipient areas because a proper separation of a graft vascular pedicle and the choice of the source of feeding in the recipient area determine the short-term outcome of the surgery and graft retention $[3,4]$.

The literature review showed that the majority of vascular complications in patients after microsurgical toe transplantation were associated with inaccuracies in the technique of graft separation, lack of graft blood supply because of improper choice of feeding arteries, and underestimation of arterial and venous bloodstream in the recipient area [5-7]. 
Several recent publications were dedicated to the peculiarities of angioarchitecture of toes in children with indications for microsurgical toe-to-hand transfers [8, 9]. According to Scherbakova (1955), the arterial blood supply to toes can be divided into 3 types:

1) dorsal - with the prevalence of $a$. dorsalis pedis;

2) plantar - with predominant development of plantar arteries;

3) uniform - with symmetrical development of both arterial trunks [10].

There are few publications on the topographical anatomy of arteries of the first intermetatarsal gap for microsurgical autografting. Thus, based on the data published by Leung et al. (1983), there are 7 types of blood supply of the first and second toes depending on the location and size of the first dorsal metatarsal artery (FDMA). However, the authors of this study did not consider the angioarchitecture and application of the first plantar metatarsal artery (FMPA) and toe transfer on plantar arteries was not studied [11].

In the authors' previous works [12], the main types of autograft feeding were specified: via the system of a. tibialis anterior $70.7 \%$ in patients with congenital pathology and $77.4 \%$ in patients with acquired pathology) and via the system of $a$. tibialis posterior $(29.3 \%$ and $22.6 \%$, respectively). In $25.9 \%$ of cases of congenital pathology and $37.9 \%$ of cases of acquired pathology, the source of feeding was the FDMA. In $17.1 \%$ of cases of congenital pathology and $16.9 \%$ of cases of acquired pathology, the feeding arterial trunk for the second toe was the first plantar metatarsal artery (FMPA) anastomosing with the deep plantar branch of the dorsalis pedis artery (DPA). According to the author, in $8 \%$ of cases, graft feeding was performed by FMPAs because of the complete absence of the system of DPAs.

Kay and Wiberg (1996) performed free toe-to-hand transfer for 40 patients aged 9 months to 14 years old. The FDMA was used in $66 \%$ of cases and the FMPA was used in $34 \%$ of cases. It was also noted that in one observation, the SMPA was used because the FDMA was damaged during the surgery [13].

The aim of the present study was to show the role and significance of the studies on the angioarchitecture of donor and recipient areas for a successful microsurgical autograft toe-to-hand transfer in children.

\section{MATERIALS AND METHODS.}

The study was based on the medical records of children that were examined and treated in the Turner Scientific Research Institute for Children's Orthopedics (TSRICO) in 2000-2018. The study included 541 patients aged 8 months to 17 years old. All children had congenital or posttraumatic deformities of upper limbs (45.2\% (244) of males and 54.8\% (297) of females). In total, 
there were 696 transfers performed. In 522 cases, there was one toe-to-hand transfer (toe II- 95\%, toes III, IV, V-5\%). In 174 cases, a block of toes II-III was transferred.

The study protocol followed guidelines for experimental investigation with human subjects in accordance with the Declaration of Helsinki and was approved by the ethics committee. Written informed consent was obtained from each patient (or official representative) before the study.

The separation of the toe autograft began with a figured section along the dorsal part of the foot in the projection of the first intermetatarsal gap. The section continued via the first and second web space to the plantar surface. Further, v. saphena magna was isolated from the surrounding tissues. The next step included the dissection of the tendon of the short first toe extensor. Further, the dorsalis pedis artery (DPA) and the first dorsal metatarsal artery (FDMA) were visualized. The section continued via the first and second web space to the plantar surface. In the first web space, the FMPA was isolated from the place of its bifurcation and further proximally to its mergence with the plantar arterial arch. The same procedure was performed for the second plantar metatarsal artery (SPMA) and the third plantar metatarsal artery (TPMA) when the graft consisted of two toes. This step included an obligatory identification of the deep arterial branch that connects the dorsal and plantar systems of blood supply. Simultaneously, the mobilization of plantar digital nerves and the tendinous toe apparatus was performed. If hypoplasia or aplasia of some arteries were revealed, the sequence of the steps during the surgery was not changed.

When the recipient area was prepared, the graft(s) was transferred on the hand. Osteosynthesis was performed with $1.0 \mathrm{~mm}$ pins. Further, anastomoses were formed between the graft tendons and nerves and the respective structures of the recipient area. A. radialis and a. ulnaris were used as recipient arteries in the majority of cases at the level of the wrist joint. The anastomosing of veins was performed with the branches $v$. basilica and v. cephalica.

In cases when the graft feeding pedicle length was insufficient (less than 4.0-5.0 cm), the anastomosing was performed with the carpal arch and (or) common palmar digital arteries. In the cases when the wrist vessels were hypoplastic (the vessel diameter was less than $1.0 \mathrm{~mm}$, slow bloodstream), the anastomoses with a. radialis and a. ulnaris were placed proximally (on the brachium). In the cases of aplasia or hypoplasia of the specified arteries, the surgeons used other brachial arteries (a. interossea posterior, a. mediana, a. brachialis). For the elongation of the graft pedicle, an autovenous insertion from $v$. saphena magna was used.

\section{RESULTS.}

The results showed that the second toe graft can be primarily fed from the pool of a. tibialis anterior, as well as a. tibialis posterior. The DPA is a continuation of a. tibialis anterior; it provided adequate blood supply for autografts in $79 \%$ of cases (550 transplants). In $21 \%$ of cases (146 grafts), the graft was fed from a. tibialis posterior because of the absence or hypoplasia of $a$. 
dorsalis pedis. The diameter of the graft vascular pedicle varied depending on the age of patients and the degree of limb development (in patients with congenital pathology). The average diameter of the feeding arteries was 1.5-2.5 mm. However, in some cases, the diameter of vessels could be 1 $\mathrm{mm}$ and less when the grafts had a short vascular pedicle (less than $3 \mathrm{~cm}$ ) because of anatomical peculiarities, i.e. at the level of metatarsal arteries.

After a standard separation of the graft vascular pedicle (in the case of a normally developed DPA), its length could be up to 6-7 $\mathrm{cm}$. For the evaluation of the intensity of graft bloodstream, the authors studied the following parameters: the color and temperature of the graft surface and the rate of capillary response. In some cases, for the evaluation of the graft tissue oxygen saturation, a pulse oximeter was used.

When the DPA is present, the blood supply of the second and third toes can be exerted by FDMAs and FMPAs. In 68\% of cases, the FDMA could be used as one of the blood-feeding vessels for the graft because it was well developed (Figure 1) and, in 32\% of cases, it was hypoplastic (less than $0.5 \mathrm{~mm}$ in diameter) or completely absent.
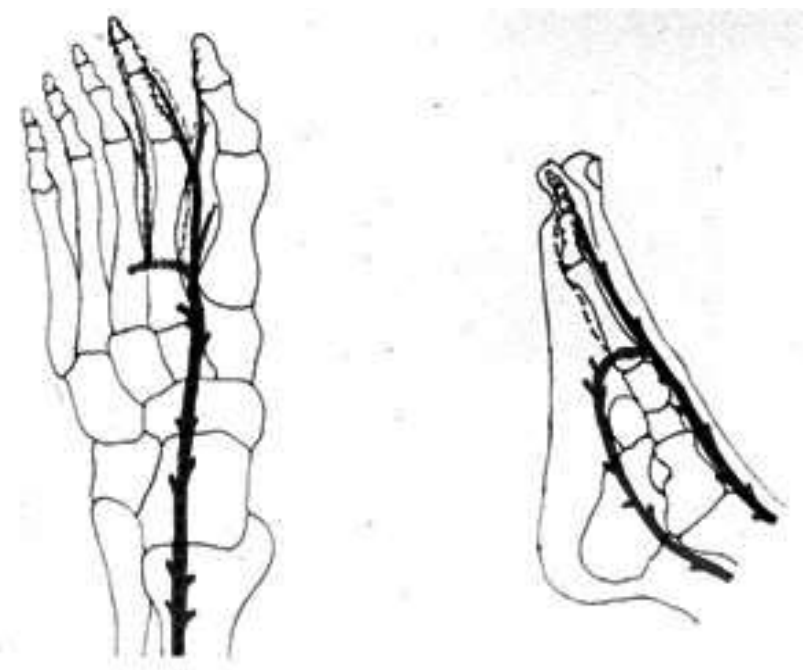

Figure 1. The prevalence of dorsal arterial blood supply for toe graft (layout)

Previous studies [12] showed that in patients with good development of the FDMA, it was not feasible to separate the other arterial trunks. However, after facing serious complications associated with the insufficient blood supply in the autograft, the authors started to separate all the dorsal and plantar arteries during further surgeries.

When the DPA and FDMA were well developed, there were different combinations of toe feeding arteries. Several cases should be highlighted when there was no connection between the FMPA and the plantar arterial arch. This artery lied under the aponeurosis in the superficial layers of the planta. In this case, the FDMA and SMPA were separated that anastomosed with the DPA via 
the deep arterial branch. The FMPA was separated at maximum possible length. When necessary, an additional microvascular anastomosis was made on the hand (Diagram 1).

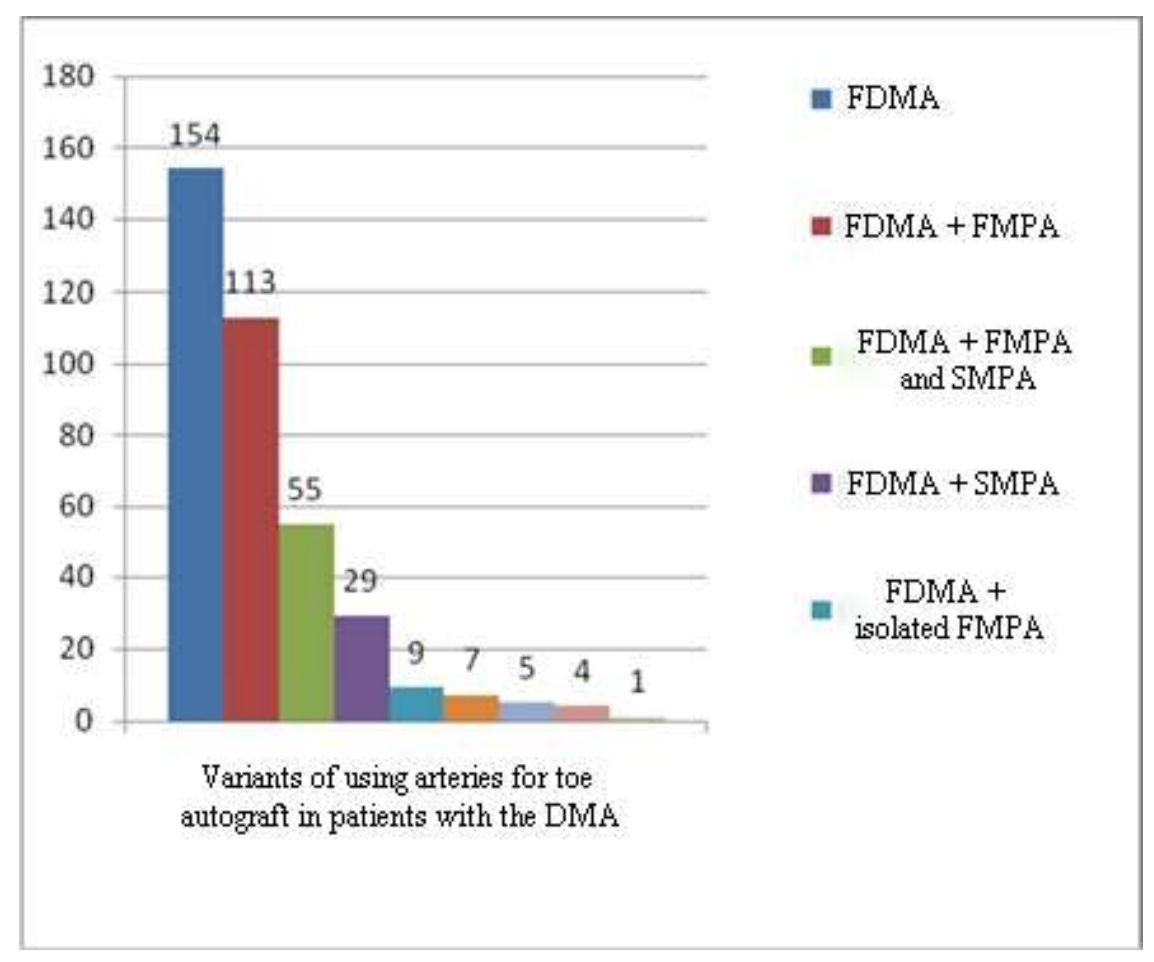

Diagram 1. Variants of blood supply of toe autografts in patients with the DMA

In patients with hypoplasia and aplasia of the DMA, the autograft was separated on the MPAs that branched off from the plantar arterial arch and via the deep arterial branch connected with the DPA (Diagram 2).

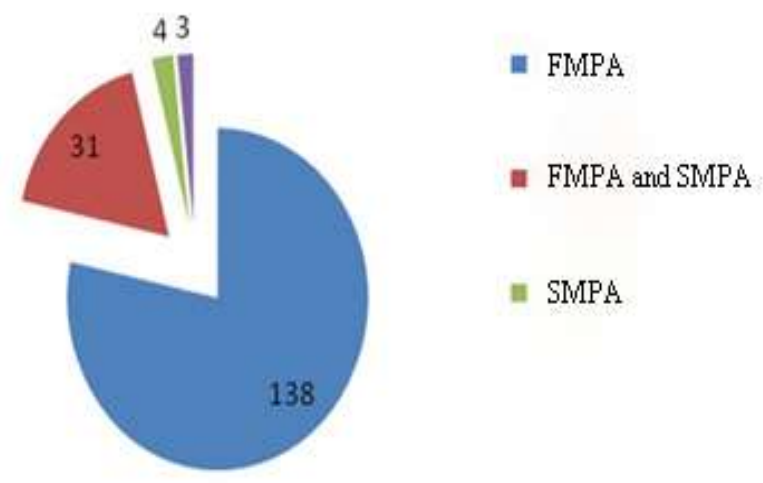

Variants of using arteries for toe autograft in patients with absence or hypoplasia of the DMA 
In $21 \%$ of cases, the DPA was hypoplastic or completely absent, which required the formation of autograft on plantar arteries. In such conditions, surgeons separated the FMPA. In 36\% of cases, the main feeding vessel was the isolated fragment of the plantar arterial arch and, in $64 \%$ of cases, only distal arterial trunks (MPAs and DMAs) were mobilized (Figures 2 and 3).

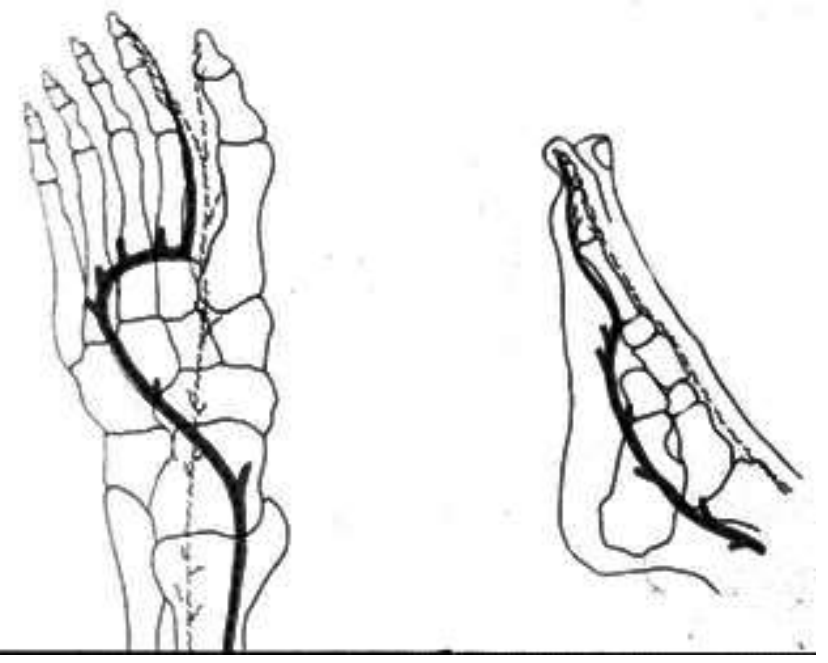

Figure 2. The variant of the graft blood supply from the system of the posterior tibial artery (layout)
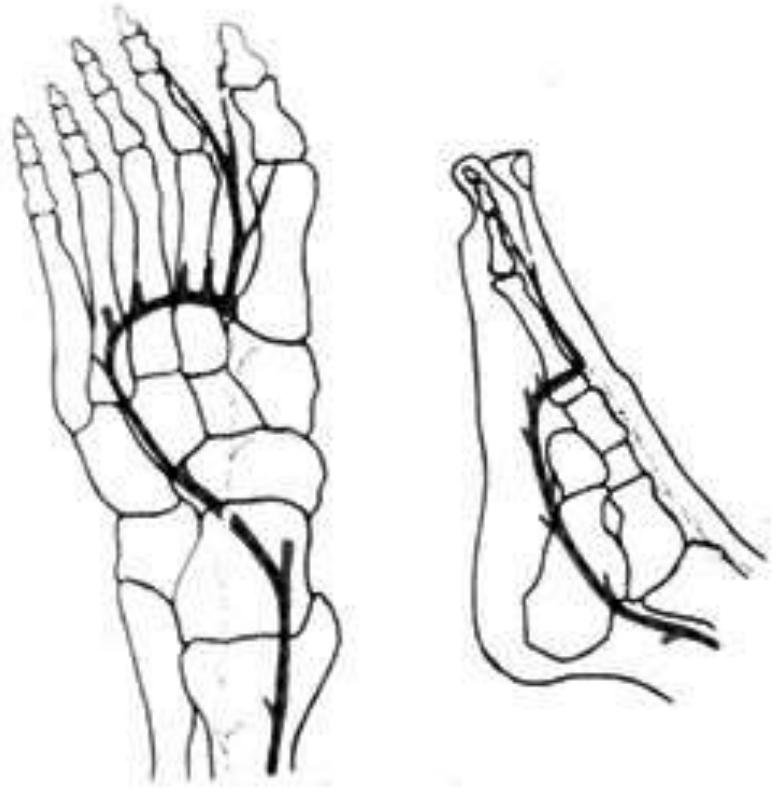

Figure 3. The variant of the graft blood supply from the plantar arterial arch that continues to the dorsal system of blood circulation (layout)

Diagrams 3 and 4 show different variants of the autograft blood supply that were performed in cases when fragments of the plantar arterial arch and distal metatarsal arteries were used. 


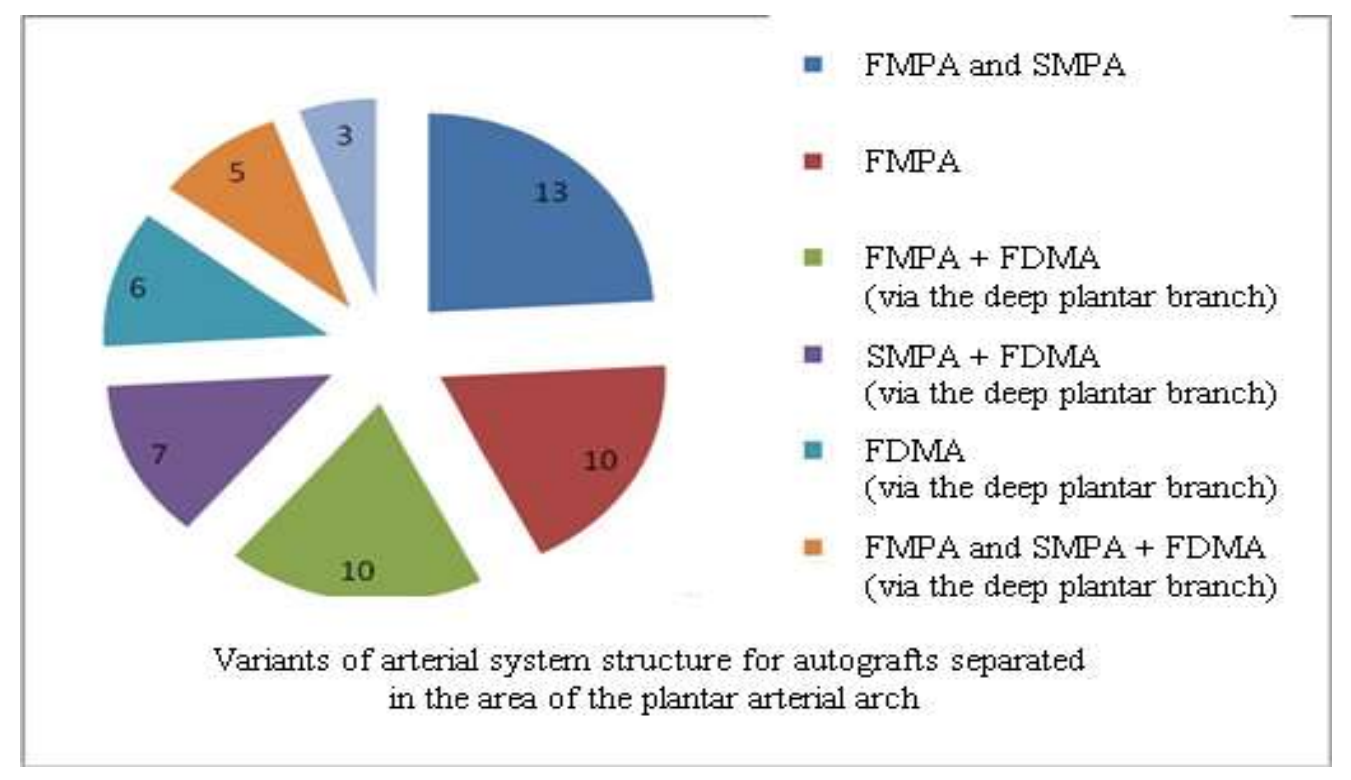

Diagram 3. Variants of blood supply of autografts separated in the area of the plantar arterial arch.
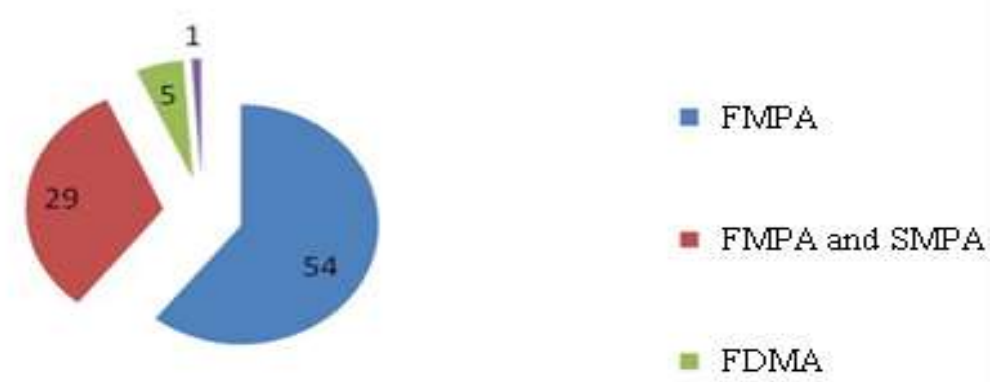

Variants of arterial system structure for autografts separated only on distal (metatarsal) arteries.

a SNPA

Diagram 4. Variants of blood supply for autografts separated on distal (metatarsal) arteries.

The principles of preparation of feeding vessels in the recipient area.

There are two main parameters to be considered during the choice and preparation of the feeding vessel in the recipient area: the proper diameter and high intensity of the bloodstream [14, 15]. The wrong evaluation of these parameters in children led to post-operational vascular complications in children caused by insufficient blood circulation in the autograft. In children with severe congenital deformities of the upper limb, hypoplasia could reach distal sections of $a$. radialis and $a$. ulnaris. In such cases, surgeons had to make arterial anastomosis proximally to the level of 
the distal third of the upper arm using autovenous insertion. In some cases, surgeons used $a$. interossea posterior, a. mediana, a. brachialis.

The choice of the feeding vessel of the upper limb is determined by the angioarchitecture of the donor area. Standard variants of vessel connection were anastomoses with $a$. radialis and $a$. ulnaris. They were made in cases when the length of the donor artery was sufficient. Vascular anastomosis with the carpal arch or common palmar digital artery was used in cases when the autograft pedicle was short (3.0 cm and less). In cases of single-step transfers of two autografts from both feet, one artery was used as a feeding vessel. If the feeding artery had a proper diameter (less than $0.9 \mathrm{~mm}$ ) and had a high rate of bloodstream, both parts of the dissected vessel were used for feeding both autografts. In this case, a. radialis, a. ulnaris or carpal arch was used as a feeding artery (Table).

Variants of vascular feeding on the upper limb

\begin{tabular}{|c|c|c|}
\hline Choice of the feeding vessel & $\begin{array}{l}\text { Transplantation of } \\
\text { one autograft }\end{array}$ & $\begin{array}{c}\text { One-step } \\
\text { transplantation of two } \\
\text { autografts }\end{array}$ \\
\hline A. radialis & 235 & - \\
\hline A. ulnaris & 84 & - \\
\hline Carpal arch & 19 & - \\
\hline A. digitalis palmaris communis & 23 & - \\
\hline A. interossea posterior & 5 & - \\
\hline $\begin{array}{l}\text { A. brachialis (branch or anastomosis "end-to-side } \\
\text { anastomosis") }\end{array}$ & 10 & - \\
\hline A. mediana & 1 & - \\
\hline $\begin{array}{l}\text { Proximal and distal fragments of } a \text {. radialis after its } \\
\text { transection }\end{array}$ & - & 107 \\
\hline $\begin{array}{l}\text { Proximal and distal fragments of } a \text {. ulnaris after its } \\
\text { transection }\end{array}$ & - & 13 \\
\hline $\begin{array}{l}\text { Proximal and distal fragments of carpal arch after its } \\
\text { transsection }\end{array}$ & - & 11 \\
\hline Two common palmar digital arteries & - & 21 \\
\hline
\end{tabular}




\begin{tabular}{|l|c|c|}
\hline Proximal fragments of $a$. radialis and $a$. ulnaris & - \\
\hline $\begin{array}{l}\text { Proximal fragment of } a \text {. radialis and } a \text {. digitalis } \\
\text { palmaris communis }\end{array}$ & - & 6 \\
\hline
\end{tabular}

Complications associated with the disturbances of blood circulation in the transferred autografts depended on numerous factors, including the size and diameter of the vascular pedicle. When the diameter of the connected vessels was sufficient (more than $2 \mathrm{~mm}$ ), the risk of clotting decreased to its minimum. When the diameters were smaller or the length of the vascular pedicle was insufficient (venous insertion was used), the risk of complications associated with clotting in the area of anastomosis increased.

\section{CONCLUSIONS.}

1. When the graft feeding was performed from a. tibialis anterior (79\%), in $68 \%$ of cases, the FDMA was well developed, and in $32 \%$ of cases, the feeding was performed only from the FMPAs. The obtained data agree with the results obtained by foreign authors $[6,9]$.

2. The method of surgical separation of toe autografts remains unchanged and does not depend on the variants of the angioarchitecture of the donor area. During the mobilization of the autograft of toe II or the block of toes II-III, it is necessary to separate all the arteries (dorsal and plantar) in order to provide adequate blood supply for the autografts and decrease the risk of the development of vascular complications in the post-operational period.

3. The proper diameter and high rate of blood flow of the feeding vessel in the recipient area are necessary for the sufficient perfusion of the graft tissues.

4. The graft retention and the successful outcome of the microsurgery depend on the quality of the mobilization of the donor vessels and the preparation of vessels in the recipient area.

Abbreviations:

DPA - dorsalis pedis artery

FDMA - first dorsal metatarsal artery

FMPA - first plantar metatarsal artery

\section{FINANCIAL SUPPORT AND SPONSORSHIP}

Nil.

\section{CONFLICTS OF INTEREST}

The authors declare no conflict of interest 


\section{SUPPLEMENTARY DATA (DOI)}

\section{REFERENCES}

1. Ed. Mironov S.P., Kotel'nikov G.P. Orthopedics: national guide [Ortopediia: natsional'noe rukovodstvo]. 2-nd edition, Moscow, GEOTAR-Media, 2013, 944 p.

2. Balashov A.V. Microsurgical autotransplantation of foot fingers in treatment of children congenital brachidactile: the dissertation of a candidate of medical sciences [Mikrokhirurgicheskaia autotransplantatsiia pal'tsev stopy pri lechenii vrozhdennoi brakhidaktilii kisti u detei: dissertatsiia kandidata meditsinskikh nauk], St. Petersburg, 2012, 182 p.

3. Ed. Laub D.R. Congenital Anomalies of the Upper Extremity. Etiology and management, Boston, Springer, 2015, 356 p. doi: 10.1007/978-1-4899-7504-1.

4. Maricevich M, Carlsen B., Mardini S. et al. Upper extremity and digital replantation. Hand (NY), 2011, vol. 4, no. 6, pp. 356-36,. doi: 10.1007/s11552-011-9353-s.

5. Goliana S.I., Tikhonenko T.I., Govorov A.V. et al. Complications after toe-to-hand transfers in children with pathologies of the hand [Oslozhneniia pri ispol'zovanii mikrokhirurgicheskoi autotransplantatsii pal'tsev stopy u detei s patologiei kisti]. Pediatric Traumatology, Orthopaedics and Reconstructive Surgery - Ortopediia, travmatologiia $i$ vosstanovitel'naia khirurgiia detskogo vozrasta, 2017, vol. 5, no. 4, pp. 16-23. doi: 10.17816/PTORS5416-23.

6. Jonescor N., Kaplan J. Indications for microsurgical reconstruction of congenital hand anomalies by toe-to-hand transfers. Hand (NY), 2013, vol. 4, no. 8, pp. 367-374. doi: 10/1007/s115520139534-5.

7. LeBlanc A., Krishman L., Sullivan C. et al. Microvascular Repair: Post-Angiogenesis Vascular Dynamics. Microcirculatation, 2012, vol. $\quad 8$, no. 19, pp. 676-695. doi: 10/1111/j/15498719.2012.00207x.

8. Wolf K-D. Raising of microvascular flaps: a systematic approach, 2nd ed. Berlin, Springer Science and Business Media, 2011, 243 p.

9. Zenn M., Jones G. Reconstructive Surgery: Anatomy, Technique, and Clinical Applications. St. Louis, MI: Quality Medical Publishing. Inc, 2012, 1849 p.

10. Shcherbakova A.A. Nekotorye osobennosti v raspredelenii arterii i nervov stopy cheloveka [Some features in the distribution of arteries and human foot nerves]. Archive of anatomy - Arkhiv Anatomii., 1955, vol. 32, no. 3, pp. 38-92. 
11. Leung P.C., Wong W.L., Lai Chi Kok. The Vessels of the First Metatarsal Web Space. The Journal of Bone and Joint Surgery, 1983, vol. 65, no. 2, pp. 235-238, doi 10.2106/00004623198365020-00014.

12. Shvedovchenko I.V., Goliana S.I. Main sources of blood supply of foot fingers used as microsurgical autograft [Osnovnye istochniki krovosnabzheniia pal'tsev stopy, ispol'zuemykh v kachestve mikrokhirurgicheskikh autotransplantatov]. Prevention, diagnosis and treatment of children musculoskeletal injuries and diseases [Profilaktika, diagnostika i lechenie povrezhdenii $i$ zabolevanii ODA u detei]. St. Petersburg, 1995, pp. 128-129.

13. Kay S.P., Wiberg M. Toe to hand transfer in children. Part 1: technical aspect. Journal of Hand Surgery, 1996, vol. 21, no. 6, pp. 723-734, doi 10.1016/s0266-7681(96)80176-8.

14. Jones N.F., Clune J.E. Thumb Amputations in Children: Classification and Reconstruction by Microsurgical Toe Transfers. The Journal of Hand Surgery, 2018, vol. 44, no. 6, pp. 519.e1519.e10, doi 10.1016/j.jhsa.2018.08.013.

15. Roger de Ona I., Garcia Villanueva A., Studer de Oya A. An Alternative Thumb Reconstruction by Double Microsurgical Transfer From the Great and Second Toe for a Carpometacarpal Amputation. The Journal of Hand Surgery, 2018, vol. 43, no. 10, pp. 955.e1-955.e9, doi: 10.1016/j.jhsa.2018.03.022. 